International Journal of

\title{
A strategic Study on Customer Engagement Improvement from the Perspective of Short Video Advertising : Take Douyin as an Example
}

\author{
Hong Jin ${ }^{1}$, Feng Yang ${ }^{2}$ \\ ${ }^{1,2}$ School of Business, Jiangxi Normal University, China
}

\begin{abstract}
Background/Objectives: This paper mainly analyzes customer engagement from the perspective of douyin advertising and provides strategies for the development of the short video industry. Methods/Statistical analysis: In this study, we try to provide new suggestions for advertising through the analysis of related cases in the review papers. Findings: In recent years, the Internet market penetration of short videos has been increasing.In addition, under the influence of the epidemic in 2020, not only web celebrity live broadcast, but also more bricks-and-mortar stores have launched live broadcast to advertise and sell products. However, the degree of customer participation in live broadcast is different. Improvements/Applications: The perspective of douyin advertising, this paper mainly analyzes the factors affecting customer participation behavior and puts forward corresponding strategies to help the development of enterprises.
\end{abstract}

\section{Index Terms}

Douyin, Douyin advertisement, Customer participation, Strategic management, SEM

\footnotetext{
Corresponding author : Hong Jin com342944219@qq.com

- Manuscript received June 15, 2020.

- Revised July 152020 ; Accepted July 29020.

- Date of publication September.

(C) The Academic Society of Convergence Science Inc.

2546-1583 $\odot 2017$ IJEMR. Personal use is permitted, but republication/redistribution requires IJEMR permission
} 


\section{INTRODUCTION}

According to the 2019 data report, the number of daily active users on January 1, 2020 exceeded 400 million. Last year, it was only 250 million. In 2019, it increased by 150 million. Merchants, especially during the epidemic period, have come to tik tok to conduct live broadcast sales. Behind the live broadcast is product endorsement and advertising.

However, as an entertainment platform, it is easy for many advertisements to cause discomfort to other users, which makes it difficult for customers to participate. Thus, one of the most important factors that affects customer engagement is advertising.

Therefore, from the perspective of douyin advertising, this paper mainly analyzes the factors affecting customer participation behavior and puts forward corresponding strategies to help the development of enterprises.

\section{LITERATURE REVIEW}

Chan et al.[1]believe that customer participation in the service process can provide customers with more choices, create customized products or services together with service providers, and better avoid the risk of inappropriate results[3]. $\mathrm{Su}$ [2] think if the customer participation is higher, the chance of the creation of management resources(such as time, skills, products and services) is bigger.

It is easier to produce more beneficial experienced stimulation. Pilar [4] etc by analyzing the questionnaire survey to 807 enterprises. And he pointed the customers participation has positive effect on enterprise product innovation and sales performance[5].

\section{ANALYSIS OF INFLUENCING FACTORS OF CUSTOMER PARTICIPATION BEHAVIOR}

\section{A. From the perspective of douyin algorithm}

In the short video cultural communication from the perspective of new media, lu xin[7] analyzed douyin and realized the accurate positioning with the help of big data algorithm.

According to the user's recent browsing habits and viewing habits implementation effect push, accurate push advertising information. At the same time, the background collect users of different excitement, conducive to the precise creation of advertising creators, to meet the user's taste, real-time push but not disgusting.

According to the analysis from this perspective, customer engagement is closely related to the content quality of the advertisement itself.
It is required to fully improve the content attraction of advertisements when selling online live broadcast, so as to increase the viewing time of advertisement videos of douyin users and increase the amount of clicks and push.

\section{B. From the perspective of advertising content}

In the evolution and reconstruction of the mode of public opinion monitoring in the era of big data, liu qi mentioned that in the era of media integration, resource sharing has weakened the creativity of local radio programs, and the means of imitation seems to be the most economical and effective.

Although local radio programs do not have the platform advantages and popularity of central media, they still follow the style and mode of central media.

However, if the monopoly of regional communication in the face of national and whole network competition is broken, then simple imitation will become an embarrassing situation like "doing nothing but imitating others"[8].

From this perspective, customer participation is closely related to the innovation of advertising content.

Therefore, the content of advertisement must be actively innovated to form the interest value drive. Put an end to the blind imitation, can not always "follow the lead" to treat the symptoms but not the root cause, which not only produces the aesthetic fatigue of the public, but also damage the corporate image, and even lead to "powder off".

\section{From the perspective of advertisers}

Henry Jenkins once said that fans are like nomads, always on the move, and with the fragmentation of the Internet, it's easy to be distracted[9, 10].

From this analysis, customer participation is closely related to their own emotional needs and emotional resonance.

Therefore, live broadcast advertising should consider the preferences of the audience and generate emotional resonance through the drive of emotional value.

\section{STRATEGIES TO IMPROVE CUSTOMER ENGAGEMENT}

\section{A. Advertising push: arouse interest in watching and expand the range of advertising radiation}

When making advertisements, merchants should fully integrate the consumer taste associated with their products into the advertising content to stimulate the interest of the audience.

Through the interest value orientation to increase the user's viewing time, provide thumb up volume, 
and so on, so as to increase the push volume, expand the radiation range, and improve customer engagement.

\section{B. Advertising content: strengthen content innovation to form core competition}

When selling their own products, advertisements should be relevant to the products and have a high degree of correlation with the characteristics of the products.

And the combination of product characteristics, the integration of the corresponding cultural elements and the trend of The Times, the formation of the core competitiveness of advertising.

Only in this way can customers stay in the "foot" and attract customers to participate. For example, haidilao has special service model.

\section{The advertisers}

Advertisers themselves: to set up their own distinctive people, the formation of a unique label

When doing live broadcast and advertising, sales staff can gradually form their own unique image, which can stimulate customer memory and make people impressed. This also gives advertising a silent boost, increasing customer engagement.

Advertisers and fans: enhance the emotional resonance of fans, strengthen the viscosity of fans

When advertising should stand on the needs of customers to give them spiritual emotional satisfaction, so easy to enhance the trust and dependence of fans, strengthen the viscosity of fans. In this way, customers will be more willing to participate in the interaction, comments and other links, and it is also conducive to the realization of product transaction in a short time.

\section{Conclusion}

In this study, we proposed a strategy for advertising.

Therefore, in this study, we conducted various case analyzes of Gwango. As a result, ad push can arouse interest for viewing and expand the range of ad radioactivity.

Strengthening Content Innovation for Forming Core Competition When selling a product of its own, advertising can form its own label to set its own unique person with the advertising content associated with the product. become able to.

The results provide significant suggestions to advertisers through strategies such as ad push and content.

\section{Acknowledgments}

This study is supported by the National Natural Science Foundation of China (No.71962014) and Jiangxi Universities Humanities and Social Sciences Research on Young Fund (GL17115).

\section{REFERENCES}

[1] Chan, k.w., Yim, c. k., \& Lam, s.s.k.(2010) Is customer participation in value creation a double-edged sword?Evidence from professional financial services across cultures.Journal of Marketing,74(3):48-64.

[2] Su, c. J., Lebrun, a. M., Bouchet, p.,Et al.(2016).Tourism participation and preference-related belief in co-creating value of experience:a nature-based perspective.Service Business, 10(4):1-24.

[3] Yu hongyan, Hong liang, Xu junjie.(2020) Is enterprise support conducive to customer participation in value creation?-- empirical analysis from online customization industry.Business research, (2):1-8.

[4] CARBONELL P, rodriguez-escudero A I,PUJAEI d.(2009) Customer involvement in new service development: an examination of antecedents and outcomes.Journal of Product Innovation Management, 26 (5) : 536-550.

[5] Li jing et al.(2018) Measurement of customer engagement based on enterprise product development performance." computer integrated manufacturing system, vol. 24. 8 : 20452052.

[6] Chen ying. (2019) Reflection on short video advertising in the new media era--a case study of douyin short video platform. Publishing wide Angle, (16) : 68-70.

[7] Lu xin. (2019).Cultural communication analysis of short video from the perspective of new media -- a case study of douyin short video. Chinese character culture, (18) : 28-29.

[8] Liu qi.(2017).Evolution and reconstruction of the mode of public opinion monitoring in the era of big data . Media, (1) : 77-79.

[9] Henry Jenkins(2016). IXtextual poachers: TV fans and participatory culture, Peking University press, 36-38.

[10] Jin, H., \& Yan, J. (2020). A Study on the Factors that Influence Wearable Users' Quantified Self Based on UTAUT Model. INTERNATIONAL JOURNAL OF EMERGING MULTIDISCIPLINARY RESEARCH (IJEMR), 4(2), 7-10. 